\title{
Clinical and epidemiological behavior analysis of thyroid cancer at the "Dr. José Eleuterio González" University Hospital
}

\author{
Edgar A. Montemayor-Garza1, Erick R. Guerra-Bocanegra', Luis A. Ceceñas-Falcón², Max Molina-Ayala², \\ Gabriel G. Ibarra-Núñez ${ }^{1}$, Alexandra C. Cavazos-Benítez'1 Laura C. Hernández-Villarreal³, \\ Rolando López-Rodríguez ${ }^{4}$, Gerardo Sánchez-Solis ${ }^{2}$, and Jesús Z. Villarreal-Pérez ${ }^{1,2 *}$
}

${ }^{1}$ Endocrinology Service; "Dr. José Eleuterio González" University Hospital; ${ }^{2}$ Pathologic Anatomy and Cytopathology Service, at "Dr. José Eleuterio González" University Hospital; ${ }^{3}$ School of Medicine. Universidad Autónoma de Nuevo León, Nuevo Leon, Mexico

\begin{abstract}
Objective: This work aimed to establish the epidemiological clinical profile of thyroid cancer (TC) in a Northeastern Mexican Hospital's population and establish associations between socio-demographic variables with clinical and paraclinical variables and compare them with the USA trends published by H. Lim. Methods: A descriptive, retrospective, and cross-sectional study was conducted, which included records with the histopathological diagnoses of TC from 2012 to December 2019. Results were analyzed using central tendency, frequency, and percentage tables. The comparison between the clinical and epidemiological variables of our data and the results reported in the U.S. by H. Lim was performed by a proportion analysis. The association between gender and categorical variables was done through the Chi-square test using SPSSV.23.0. Results: Among the 290 patients (mean [SD] age at diagnosis, 46.35 [15.19] years; 248 [85.52\%] were women) diagnosed with TC. Papillary TC was the most common histological type $(92.76 \%)$. A statistically significant difference was found $(p<0.05)$ in the proportion of men and women, being younger or older than 55 years of age, between 20-39 and 60-79 years old, suffering from the subtypes of papillary or follicular carcinoma and among all categories of clinical stage. Conclusion: TC occurs mostly in women between 40 and 59 years old, presenting predominantly papillary thyroid carcinoma in the early clinical stages, with a low-risk of recurrence. Despite the limitations, there are not recent studies in Mexico about it. Thus, it is imperative to constantly update the trends of this pathology to benefit patients and health services.
\end{abstract}

Key words: Thyroid cancer. Epidemiology. Endocrinology. Clinical pathology.

\section{Introduction}

Thyroid cancer (TC) is the most common malignant neoplasm of the endocrine system, representing $3.8 \%$ of all new cancer patients in the U.S. alone and being the ninth most common form of cancer in general. In Mexico, it is the sixth most common cause of cancer in women, and in men, it represents the $23^{\text {rd1 }}$.
In recent years, there has been a constant and considerable increase in the incidence of this pathology worldwide. One of the main reasons is the increase in the use of imaging diagnostic methods, which has led to greater incidental detection of small tumors ${ }^{2}$. According to American literature, TC incidence rates have increased by 211\% between 1975 and 2013, with thyroid

\footnotetext{
Correspondence:

*Jesús Z. Villarreal-Pérez

E-mail: zacvilla@yahoo.com.mx

Available online: $24-12-2020$

Date of reception: 13-07-2020 DOI: 10.24875/RMU.20000064

Medicina Universitaria. 2020;22(4):165-171 www.medicinauniversitaria.org (http://creativecommons.org/licenses/by-nc-nd/4.0/).
} 
papillary carcinoma being the most common yet less aggressive subtype ${ }^{3}$.

Knowing the epidemiology and the clinical characteristics of a specific pathology in a determined geographical zone allows us to detect people at risk of suffering from this condition, therefore performing timely interventions and deciding on the proper treatment. In Mexico, we do not have enough publications on the effects of this pathology in our population. Some were published over 20 years ago and are limited in sample size, which is the case for a study published by Rodriguez-Cuevas in $1993^{4}$. Moreover, it is important to highlight that the Mexican clinical practice guidelines for TC base their recommendations on American statistics, which forces us to search for the current statistics of frequency and the clinical characteristics of thyroid neoplasia in our environment.

The present study aims to describe the clinical-epidemiological profile of TC among the population of patients of the "Dr. Jose E. Gonzalez" University Hospital. Thus establishing associations between socio-demographic, clinical, and paraclinical variables. A secondary objective was to contrast our results with the profile of the disease in the United States of America published by LIM in 2017, since it is one of the studies with the greatest population studied over the longest time, offering the opportunity to compare our center with the best statistics to date endorsed by the National Cancer Institute ${ }^{3}$.

\section{Methodology}

A descriptive study was conducted in collaboration with the Endocrinology and Pathology Service at the "Dr. Jose E. Gonzalez" University Hospital. The inclusion criteria were as follows: patients of either gender, any age group, with a confirmed diagnosis with a biopsy classified by histological subtype, from January 2012 to December 2019, patients with a complete clinical file, pathology report, and extension studies, belonging to the population of admissions and discharges during the specified period (total population of 297,000). The following criteria were considered for exclusion: patients with benign thyroid pathology, patients with a malign neck pathology whose main origin was not the thyroid gland, patients from a different institution, incomplete files, and/or lack of information classified as thyroid carcinoma.

We gathered the information of those patients who had a histopathological diagnosis of TC from January 2012 to December 2019 and those who attended the
Endocrinology Service and in whom the presence of this ailment was confirmed during this period.

All data were collected from the Pathology and Cytopathology Service files and database. A revision of the existent bibliography was conducted for better comprehension and analysis of the frequency of this pathology in the rest of the world using the following MeSH terms: thyroid neoplasms, thyroid neoplasms/ pathology, thyroid neoplasms/epidemiology, TC, papillary, TC, papillary/pathology, TC, papillary/epidemiology, incidence, adult, incidence, and epidemiology, from 2014 to 2019. The results were analyzed through frequency and percentage charts, as well as with central tendency measures. We calculated the risk of recurrence using the American Thyroid Association scale (ATA) $2015^{5}$ and simultaneously using the TNM criteria for differentiated, anaplastic, and medullary TC of the American Joint Committee on Cancer (AJCC) $6^{\text {th }}$ and $8^{\text {th }}$ edition ${ }^{6}$. We searched for the previous reports of fine needle aspiration (FNA) Biopsy classified by the Bethesda system ${ }^{7}$. The comparison between clinical and epidemiological variables of the obtained data and the reported results in the American population by $\mathrm{Lim}^{3}$ in 2017 was conducted through a ratio analysis using Pearson's Chi-square test, taking a value of $p<0.05$ as statistically significant. The relationship between gender categories and the studied categorical variables was conducted through Pearson's Chi-square test, presenting statistical significance if the value was $p<0.05$. The odds ratio was calculated using a crossed product estimation, after closely associating the categorical variables by Pearson's Chi-square test. Both analyses were conducted using the statistical software SPSS $\mathrm{V}-23.0^{8}$

\section{Results}

A total of 485 cases were reviewed between January 2012 and December 2019, finding 290 patients with a confirmed TC diagnosis.

Out of the 290 reported cases, $14.48 \%(n=42)$ were male, and $85 \%(n=248)$ were female, with a close-ratio of 1:6. The average age was 46.35 years old, with a standard deviation of 15.19 . The age range with the highest number of cases was the one 40-59 (Table 1).

Histopathological diagnoses found in the 290 reviewed cases are shown in table 1. Papillary carcinoma represented $92.76 \%(n=269)$, follicular carcinoma constituted $3.45 \%(n=10)$, medullary carcinoma was $2.07 \%$ ( 6 cases), and anaplastic carcinoma was $1.75 \%$ 
Table 1. Description of clinical and epidemiological parameters of patients with thyroid cancer at the "Dr. José Eleuterio González" University Hospital

\begin{tabular}{|c|c|}
\hline & $\begin{array}{l}\text { Endocrinology Service, } \\
\text { University Hospital "Dr. José } \\
\text { Eleuterio González" n = } 290\end{array}$ \\
\hline & Total n (\%) \\
\hline $\begin{array}{l}\text { Gender } \\
\text { Male } \\
\text { Female }\end{array}$ & $\begin{array}{c}42(14.48) \\
248(85.52)\end{array}$ \\
\hline $\begin{array}{l}\text { Age }(\text { years) } \pm S D \\
<55 \text { years } \\
\geq 55 \text { years } \\
<20 \text { years } \\
20-39 \text { years } \\
40-59 \text { years } \\
60-79 \text { years } \\
\geq 80 \text { years }\end{array}$ & $\begin{array}{c}46.35( \pm 15.19) \\
198(68.28) \\
92(31.72) \\
5(1.72) \\
102(35.17) \\
122(42.07) \\
54(18.62) \\
7(2.41)\end{array}$ \\
\hline $\begin{array}{l}\text { Histopathological diagnosis } \\
\text { Papillary carcinoma } \\
\text { Follicular carcinoma } \\
\text { Medullary carcinoma } \\
\text { Anaplastic carcinoma }\end{array}$ & $\begin{array}{l}269(92.76) \\
10(3.45) \\
6(2.07) \\
5(1.75)\end{array}$ \\
\hline $\begin{array}{l}\text { Clinical stage AJCC/TNM } \\
\text { Stage I } \\
\text { Stage II } \\
\text { Stage III } \\
\text { Stage IV-A } \\
\text { Stage IV-B } \\
\text { Stage IV-C }\end{array}$ & $\begin{array}{c}213(73.56) \\
43(14.83) \\
17(5.86) \\
7(2.41) \\
9(3.1) \\
1(0.34)\end{array}$ \\
\hline $\begin{array}{l}\text { Tumor size }(\mathrm{cm}) \pm \text { SD } \\
\text { Extension } \\
\text { - Without capsular infiltration } \\
\text { - Capsular infiltration without } \\
\text { extracapsular infiltration } \\
\text { - Capsular infiltration and } \\
\text { extracapsular invasion }\end{array}$ & $\begin{array}{c}3.23( \pm 2.71) \\
116(38.96) \\
42(14.48) \\
132(45.51)\end{array}$ \\
\hline
\end{tabular}

Adapted from Haddad Rl, et al. ${ }^{6}$

$(n=5)$. According to the clinical stage according to the $8^{\text {th }}$ edition of the AJCC TNM classification, they were distributed as follows: Stage I: $73.56 \%(n=213)$, Stage II: $14.83 \%(n=43)$, Stage III: $5.86 \%(n=17)$, Stage IVA: $2.41 \%(n=7)$, Stage IV-B: $3.1 \%(n=9)$, and Stage IV-C: $0.34 \%(n=1)$. Tumoral extension was present without capsular infiltration in $38.96 \%(n=116)$, with capsular infiltration without perforation in $14.48 \%$ $(n=42)$ and capsular infiltration with extracapsular invasion (perithyroidal tissue) in $45.51 \%(n=132)$ of cases.

Our data were also compared by gender (Table 2). The average age in males who presented TC was 47.83 years (SD \pm 16.9 ), and the average age in females was 46.52 years $(S D \pm 15.4)$. The most frequent age range of presentation was $40-59$ years for both genders. The most frequent histopathological diagnosis for both groups was papillary carcinoma, finding it in men in $88.09 \%(n=37)$ and in women in $93.54 \%(n=232)$ of cases.

In males, both anaplastic and medullary carcinomas occurred with the same incidence, corresponding to $4.76 \%(n=2)$, followed by follicular carcinoma, which was presented in $2.38 \%(n=1)$ of cases. In the female population, the data were different, since the second most frequent was follicular carcinoma with $3.62 \%$ $(n=9)$, followed by anaplastic carcinoma with a total of $1.61 \%(n=4)$, and last was medullary carcinoma with $1.2 \%(n=3)$.

Regarding clinical stage, comparison by gender showed the following: In men: Stage I: $61.9 \%(n=26)$, Stage II: $16.7 \%(n=7)$, Stage III: $9.5 \%(n=4)$, Stage IV-A: $9.5 \%(n=4)$, Stage IV-B: $2.4 \%(n=1)$, and Stage IV-C with 0 cases; In women the obtained data were: Stage I: $75.4 \%(n=187)$, Stage II: $14.5 \%(n=36)$, Stage III: $5.2 \%(n=13)$, Stage IV-A: $1.2 \%(n=3)$, Stage IV-B: $3.2 \%(n=8)$, and Stage IV-C: $0.4 \%(n=1)$. The lower percentage in men stands out in Stage I compared to the percentage in women $(p=0.027)$ as well as the greater percentage of Stage IV-A in men versus women $(p \leq 0.001)$ (Table 2$)$.

In relation to tumoral extension in men, we found the following data: without capsular infiltration in 33.3\% $(n=14)$, with capsular infiltration without perforation in $2.38 \%(n=1)$, and capsular infiltration with extracapsular invasion in $64.28 \%(n=27)$ of cases. In women, the data were as follows: without capsular infiltration in $41.12 \%(n=102)$, with capsular infiltration without perforation in $16.53 \%(n=41)$, and capsular infiltration with extracapsular invasion in $42.33 \%$ $(n=105)$ of cases. The percentage of extracapsular infiltration was greater in men compared to women $(p=0.008)$.

The risk of recurrence, according to the ATA Scale $2015^{5}$, was classified as low risk in $50.69 \%(n=147)$, intermediate risk in $32.76 \%(n=95)$, and high risk in $16.55 \%$ (48 cases) (Table 3).

Low risk of recurrence was the most common for both genders, occurring in $42.85 \%(n=18)$ in men and $52.01 \%(n=129)$ in women. Intermediate risk in men was $35.71 \%(n=15)$, and in women $32.25 \%(n=80)$, and when the risk was high in men with $21.42 \%(n=9)$ it was greater than in women with $15.72 \%(n=39)$. The difference was not statistically significant. Nevertheless, when assessing the association of the risk of presenting clinical Stage IV-A with gender, we found that being a man is a risk factor to present said clinical 
Table 2. Comparison by gender of the clinical and histopathological parameters

\begin{tabular}{|c|c|c|c|}
\hline \multirow[b]{2}{*}{ Gender } & \multicolumn{2}{|c|}{$\begin{array}{c}\text { Endocrinology Service, University Hospital "Dr. José } \\
\text { Eleuterio González" n = } 290(\%)\end{array}$} & \multirow[t]{2}{*}{ p-value } \\
\hline & Men & Women & \\
\hline $\begin{array}{l}\text { Age (years) } \pm S D \\
<20 \text { years } \\
20-39 \text { years } \\
40-59 \text { years } \\
60-79 \text { years } \\
\geq 80 \text { years }\end{array}$ & $\begin{array}{l}47.83 \pm 16.9 \\
1(2.38) \\
15(35.71) \\
16(38.1) \\
9(21.43) \\
1(2.38)\end{array}$ & $\begin{array}{l}46.52 \pm 15.4 \\
4(1.61) \\
87(35.08) \\
106(42.74) \\
45(18.15) \\
6(2.42)\end{array}$ & $\begin{array}{l}0.617 \\
0.545 \\
0.937 \\
0.573 \\
0.613 \\
0.988\end{array}$ \\
\hline $\begin{array}{l}\text { Histopathological diagnosis } \\
\text { Papillary carcinoma } \\
\text { Follicular carcinoma } \\
\text { Anaplastic carcinoma } \\
\text { Medullary carcinoma } \\
\text { All groups }\end{array}$ & $\begin{array}{c}37(88.09) \\
1(2.38) \\
2(4.76) \\
2(4.76)\end{array}$ & $\begin{array}{c}232 \text { (93.54) } \\
9(3.62) \\
4(1.61) \\
3(1.2)\end{array}$ & $\begin{array}{c}0.204 \\
0.682 \\
0.210 \\
0154 \\
0.209^{\alpha}\end{array}$ \\
\hline $\begin{array}{l}\text { Clinical stage AJCC/TNM } \\
\text { Stage I } \\
\text { Stage II } \\
\text { Stage III } \\
\text { Stage IV-A } \\
\text { Stage IV-B } \\
\text { Stage IV-C } \\
\text { All groups }\end{array}$ & $\begin{array}{l}26(61.9) \\
7(16.7) \\
4(9.5) \\
4(9.5) \\
1(2.4) \\
0(0)\end{array}$ & $\begin{array}{l}187(75.4) \\
36(14.5) \\
13(5.2) \\
3(1.2) \\
8(3.2) \\
1(0.4)\end{array}$ & $\begin{array}{c}0.067 \\
0.717 \\
0.275 \\
<0.001^{*} \\
0.770 \\
0.680 \\
0.027^{\alpha}\end{array}$ \\
\hline $\begin{array}{l}\text { Extension } \\
\text { - No capsular infiltration } \\
\text { - Capsular infiltration without extracapsular invasion } \\
\text { - Capsular infiltration with extracapsular invasion } \\
\text { All groups }\end{array}$ & $\begin{array}{c}14(33.3) \\
1(2.38) \\
27(64.28)\end{array}$ & $\begin{array}{c}102(41.12) \\
41(16.53) \\
105(42.33)\end{array}$ & $\begin{array}{l}0.340 \\
0.008^{*}\end{array}$ \\
\hline $\begin{array}{l}\text { Risk of recurrence } \\
\text { Low } \\
\text { Intermediate } \\
\text { High } \\
\text { All groups }\end{array}$ & $\begin{array}{c}18(42.85) \\
15(35.71) \\
9(21.42)\end{array}$ & $\begin{array}{c}129(52.01) \\
80(32.25) \\
39(1572)\end{array}$ & $\begin{array}{c}0.272 \\
0.659 \\
0.358 \\
0.489^{\alpha}\end{array}$ \\
\hline
\end{tabular}

Adapted from Haddad RI, et al. ${ }^{6}$

*Statistical significance was obtained using Pearson's Chi-square for categorical variables.

${ }^{\alpha} p<0.05$ was obtained by evaluating the difference in proportions between all clinical stages with the gender category using Pearson's Chi-square test

Table 3. Risk of recurrence in differentiated thyroid cancer: ATA 2015 scale

\begin{tabular}{|l|c|}
\hline & ATA Scale 2015 Total (\%) \\
\hline Low risk & $147(50.69)$ \\
Intermediate risk & $95(32.76)$ \\
High risk & $48(16.55)$ \\
\hline
\end{tabular}

Adapted from Haddad Rl, et al. ${ }^{6}$

stage with an O.R. of $8.59(\mathrm{Cl} 95 \% 1.181-38.91)$ and a value of $p<0.001$. Furthermore, a significant association was found between belonging to the male gender and presenting extracapsular invasion, with an O.R. of $1.51(\mathrm{Cl} 95 \% 1.16-1.98)$ and a value of $\mathrm{p}<$ 0.008 (Table 2).

Out of the 290 confirmed TC cases, $53.79 \%(n=156)$ were found with the presence of angiolymphatic invasion, and here there were no significant differences between men and women (59.52\% vs. $52.82 \%)$.

In table 4, there is a comparison between the clinical and epidemiological data obtained at our center and the results reported by the article "Trends in Thyroid Cancer Incidence and Mortality in the United States, 19742013"3. When conducting the proportions analysis, a statistically significant difference was found with a value of $p<0.05$ in the following cases: men and women ratio, being younger or older than 55 years of age, being between 20-39 and 60-79 years, suffering the papillary or follicular subtypes of carcinoma, and among all the clinical stages.

A comparison of the frequency of papillary cancer by gender was conducted in the studied population as well as in the American population, finding it in men $13.75 \%$ 
Table 4. Comparison of clinical and epidemiological parameters of thyroid cancer among a population of the University Hospital “Dr. José Eleuterio González” and the SEER-9 Registry Database, 1974-2013³

\begin{tabular}{|c|c|c|c|}
\hline & $\begin{array}{l}\text { Endocrinology Service, University Hospital } \\
\text { "Dr. José Eleuterio González" n = } 290\end{array}$ & $\begin{array}{l}\text { SEER-9 Registry Database } \\
1974-2013 \mathrm{n}=77,276\end{array}$ & p-value ${ }^{f}$ \\
\hline & Total (\%) & Total (\%) & \\
\hline $\begin{array}{l}\text { Gender } \\
\text { Male } \\
\text { Female }\end{array}$ & $\begin{array}{c}42(14.48) \\
248(85.52)\end{array}$ & $\begin{array}{l}19,063(24.7) \\
58,213(75.3)\end{array}$ & $\begin{array}{l}<0.001 \\
<0.001\end{array}$ \\
\hline $\begin{array}{l}\text { Age (years) + SD } \\
<55 \text { years } \\
\geq 55 \text { years } \\
<20 \text { years } \\
20-39 \text { years } \\
40-59 \text { years } \\
60-79 \text { years } \\
\geq 80 \text { years }\end{array}$ & $\begin{array}{c}46.35( \pm 15.19) \\
198(68.28) \\
92(31.72) \\
5(1.72) \\
102(35.17) \\
122(42.07) \\
54(18.62) \\
7(2.41)\end{array}$ & $\begin{array}{c}41,765(54.07) \\
35,511(45.95) \\
1,794(2.3) \\
23,877(30.9) \\
32,188(41.7) \\
16,877(21.8) \\
2,540(3.3)\end{array}$ & $\begin{array}{c}<0.001 \\
<0.001 \\
0.6318 \\
0.007 \\
0.061 \\
<0.001 \\
0.405\end{array}$ \\
\hline $\begin{array}{l}\text { Histopathological diagnosi } \\
\text { Papillary carcinoma } \\
\text { Follicular carcinoma } \\
\text { Medullary carcinoma } \\
\text { Anaplastic carcinoma }\end{array}$ & $\begin{array}{c}269(92.76) \\
10(3.45) \\
6(2.07) \\
5(1.75)\end{array}$ & $\begin{array}{c}64,625(85.3) \\
8,359(11.03) \\
1,685(2.24) \\
975(1.32)\end{array}$ & $\begin{array}{c}<0.001 \\
<0.001 \\
0.396 \\
0.481\end{array}$ \\
\hline $\begin{array}{l}\text { Clinical Stage AJCC/TNM } \\
\text { Stage I } \\
\text { Stage II } \\
\text { Stage III } \\
\text { Stage IV }\end{array}$ & $\begin{array}{l}180(62.07) \\
33(11.38) \\
36(12.41) \\
41(14.14)\end{array}$ & $\begin{array}{c}25,580(67.4) \\
2,870(7.6) \\
4,562(12) \\
3,045(8)\end{array}$ & $\begin{array}{l}<0.001 \\
<0.001 \\
<0.001 \\
<0.001\end{array}$ \\
\hline
\end{tabular}

Adapted from Lim H, et al. ${ }^{3}$ and Haddad Rl, et al. ${ }^{6}$

fStatistical significance was obtained through an analysis of proportions for frequencies weighted using Pearson's Chi-square

Table 5. Comparison by gender between patients with a diagnosis of papillary thyroid carcinoma at the University Hospital versus the SEER-9 Registry Database, 1974-2013³

\begin{tabular}{|c|c|c|c|c|}
\hline \multirow[b]{2}{*}{ Gender } & \multicolumn{2}{|c|}{$\begin{array}{l}\text { Endocrinology Service, University Hospital “Dr. José } \\
\text { Eleuterio González" } n=290\end{array}$} & \multicolumn{2}{|c|}{$\begin{array}{l}\text { SEER-9 Registry Database } \\
\text { 1974-2013 n = 77,276 }\end{array}$} \\
\hline & Male (\%) & Female (\%) & Male (\%) & Female (\%) \\
\hline $\begin{array}{l}\text { Histopathological diagnosis } \\
\text { - Papillary carcinoma }\end{array}$ & 37 (13.75) & $232(86.25)$ & $15,074(23.3)$ & $49,551(76.7)$ \\
\hline
\end{tabular}

${ }^{\ell}$ Data obtained by reviewing clinical records of cases with a histopathological diagnosis of thyroid cancer between January 2012 and December 2019. Adapted from Lim H, et al. ${ }^{3}$.

( $n=37)$ and $23.3 \%(n=15,074)$, and in women $86.25 \%$ $(n=232)$ and $76.7 \%(n=49,551)$, respectively; these results are shown in table 5 .

According to the number of new cases and the annual population of hospital discharges, we calculated the incidence by years and the range of time analyzed (2013-2019). Furthermore, a graphic representation was performed to assess its variability throughout the last 7 years (Fig. 1).

Out of the total population, we were able to identify 139 previous reports of fine-needle aspiration biopsies (FNAC) classified under the Bethesda system, which are represented in table 6 . The results were: Category I: $5.75 \%(n=8)$, Category II: $6.47 \%(n=9)$, Category III: $3.60 \%(n=5)$, Category IV: $19.42 \%(n=27)$, Category V: $19.42 \%(n=27)$, and Category VI: $45.32 \%(n=63)$.

\section{Discussion}

This article is the first study of clinical and epidemiological profiles of patients with TC at our center. One result worth highlighting is the one obtained when searching for associations between belonging to a gender category and presenting a specific variable. We 


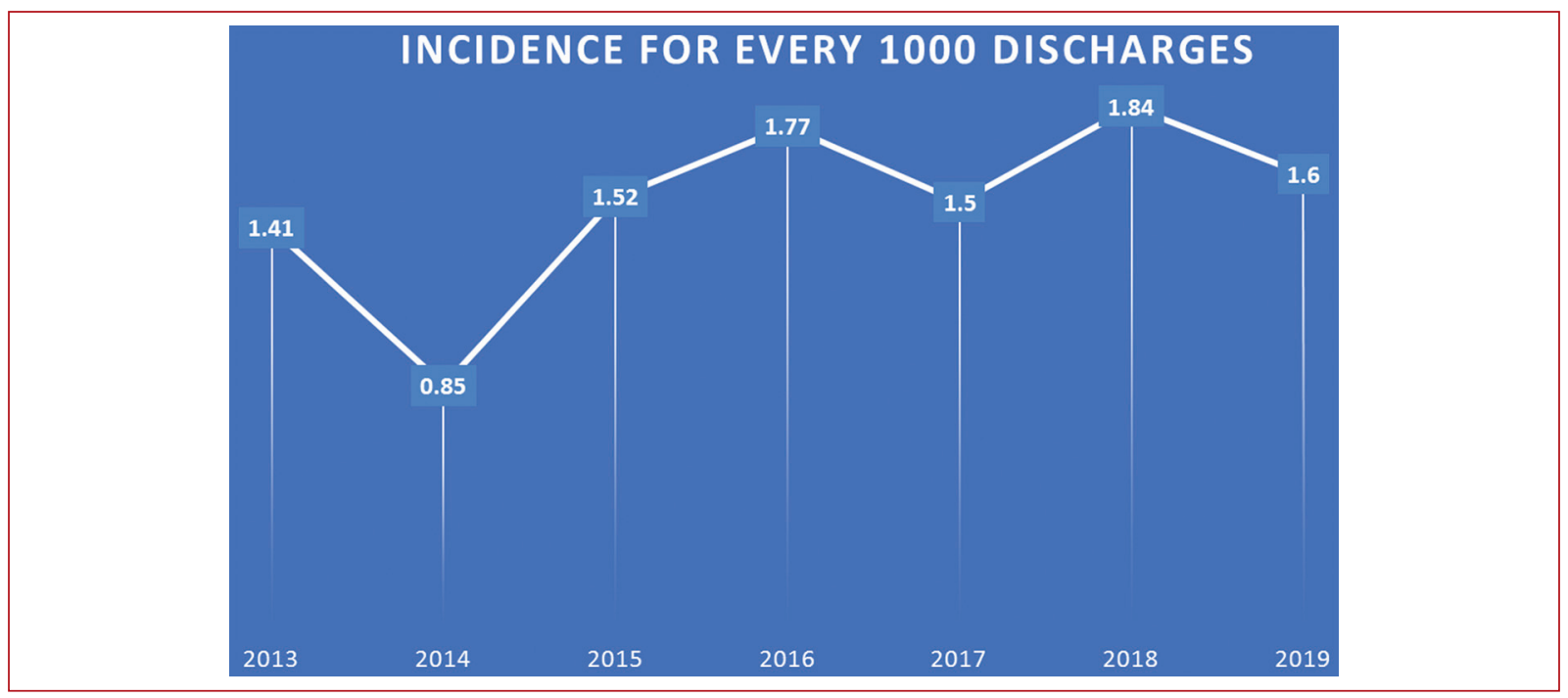

Figure 1. Incidence based on hospital discharges per year. ${ }^{f}$

fIncidence calculated based on annual hospital discharges reported by the Department of Statistics and Clinical Archives from 2013 to 2019.

Table 6. FNAB reports classified by the Bethesda system $^{f}$

\begin{tabular}{|l|c|}
\hline Bethesda & Number of cases (\%) \\
\hline I & $8(5.75)$ \\
\hline II & $9(6.47)$ \\
\hline III & $5(3.60)$ \\
\hline IV & $27(19.42)$ \\
\hline V & $27(19.42)$ \\
\hline VI & $63(45.32)$ \\
\hline Total & 139 \\
\hline
\end{tabular}

Adapted from Crippa $S$, et al.?

obtained a statistically significant link between being male and presenting an IV-A clinical stage and thyroid extracapsular invasion when performing the analysis. This result caught our attention since it shows that being a man among our studied population is linked to a greater risk of presenting an advanced clinical stage, hence an unfavorable prognosis.

Of the patients' characteristics at our hospital, there was a male-female ratio of $6: 1$, greater than that reported by domestic sources $(2-5: 1)^{1}$ and double reported by Lim in the American population $2017(3: 1)^{3}$. A mean age of 49.35 years was identified, which does not differ from those described in recent years (48,
$46.4)^{3,4}$. The result regarding the different frequencies of the histopathological type did not show any change in the predominance of thyroid papillary cancer $(92.76 \%)$ over the other subtypes, also being the most common histopathological type reported in our country $(80-90 \%)^{1}$ just as in the U.S. $(85.3 \%)^{3}$. Concerning the clinical stage at the moment of diagnosis, clinical Stage I $(62.07 \%)$ was the most frequent in our hospital, which concurs with American literature (67.4\%) ${ }^{3}$.

It is worth mentioning that at least in our hospital, over $50 \%$ of patients present a low risk of recurrence (147 cases), which indicates that a considerable percentage will have a favorable prognosis at 5-10 years ${ }^{5}$. However, it is also important to consider that approximately a seventh of patients (16.55\%) presented a high risk of recurrence (48 cases).

Despite the limitations of our study concerning sample size, racial differences, the presence or absence of risk factors, and the quality of our health-care system, to name a few; the similarities regarding population ratios between variables in the results obtained in our center as well as in those reported by $\mathrm{Lim}^{3}$ are worth noting, these included: being under 20 years of age $(p$ $=0.6318)$, being between 40 and 59 years of age $(p=$ $0.061)$ and over $80(p=0.405)$; similarly, suffering from the histological subtype of medullary thyroid $(p=0.396)$ or anaplastic $(p=0.481)$ carcinoma. On the other hand, ratios between gender variables ( $p \leq 0.001)$, being between 20 and 39 years of age $(p=0.007)$ or 60 and 79 $(p \leq 0.001)$, and any classification of the clinical stage 
(I-IV) $(p \leq 0.001)$ showed statistically significant differences between the analyzed populations.

The results regarding yearly incidence (2013-2019) of TC in our environment based on hospital discharges are shown in figure 1. It displays stability over the past 5 years. However, it would be preferable to have data of a more extended time to assess the variability or a possible increase in the number of years by case.

The Bethesda System ${ }^{7}$ establishes a classification of the results of fine-needle aspiration cytology in six. It estimates the risk of malignancy, guiding toward the more adequate treatment for the studied thyroid nodule. In our population, $<50 \%$ of patients had a preliminary FNAC study. In addition, $35 \%$ of patients who underwent a pre-operative FNAC reported Bethesda I-IV, which is considered non-suspicious of malignancy. The latter indicates a low sensitivity for this test and emphasizes the need to develop complementary methods that increase the sensitivity and specificity of the cytology ${ }^{9}$.

Compared with an Asian population, according to Du et al. $^{10}$, in a study from 1972 to 2014 shows no significant differences between Mexican and Asian populations. Therefore, both have similar behavior to those of the world's statistics.

The present research results allow us to have a current idea of the epidemiological behavior of thyroid carcinoma in the Mexican population. This, in addition to the improvement in diagnostic methods of pathology, stresses the importance of the standardization of FNAC and cytology as an approach for the thyroid nodule with suspicion of malignancy, accompanied by a tight follow-up leading to an early diagnosis, and thus a greater survival rate for the patient.

\section{Conclusion}

We can conclude that our hospital's TC does not differ in terms of clinical and epidemiological behaviors with those observed internationally regarding age, gender, histological type, clinical stage, and risk of recurrence.

Despite the limitations that this article presents, there have been no recent studies that assess the characteristics of this pathology in the past 20 years in Mexico. The "Dr. Jose E. Gonzalez" University Hospital is a third level reference center in Northeastern Mexico. Therefore, a constant update of the clinical and epidemiological profile of this pathology is imperative to be able to benefit patients and health-care services.

Given the lack of current, relevant information on this topic in our country, the data presented are of great relevance.

\section{Acknowledgments}

Our deepest gratitude to the Endocrinology, Pathology Services and the Clinical Archives Department of the University Hospital for providing the facilities to carry out this research and allowing collaboration to achieve the desired results

\section{Conflicts of interest}

The authors declare that there are no conflicts of interest between the authors of this research.

\section{Funding}

This research did not receive funding of any kind.

\section{Ethical disclosures}

Protection of human and animal subjects. The authors declare that no experiments were performed on humans or animals for this study.

Confidentiality of data. The authors declare that they have followed the protocols of their work center on the publication of patient data.

Right to privacy and informed consent. The authors declare that no patient data appear in this article.

\section{References}

1. Guía de Práctica Clínica. Diagnóstico y Tratamiento del Tumor Maligno de Tiroides. México: Secretaría de Salud; 2009.

2. Vaccarella S, Franceschi S, Bray F, Wild CP, Plummer M, dal Maso L. Worldwide thyroid-cancer epidemic? The increasing impact of overdiagnosis. N Engl J Med. 2016;375:614-7.

3. Lim H, Devesa SS, Sosa JA, Check D, Kitahara CM. Trends in thyroid cancer incidence and mortality in the United States, 1974-2013. JAMA. 2017;317:1338-48

4. Rodriguez-Cuevas S, Almendaro SL, Cardoso JM, Maya ER. Papillary thyroid cancer in Mexico: review of 409 cases. Head Neck. 1993;15:537-45.

5. Haugen BR, Alexander EK, Bible KC, Doherty GM, Mandel SJ, Nikiforov YE, et al. 2015 American thyroid association management guidelines for adult patients with thyroid nodules and differentiated thyroid cancer: the American thyroid association guidelines task force on thyroid nodules and differentiated thyroid cancer. Thyroid. 2016;26:1-133.

6. Haddad RI, Bischoff L, Busaidy NL. NCCN clinical practice guidelines in oncology (NCCN guidelines), thyroid carcinoma. NCCN Guidel. 2019;2:1-132.

7. Crippa S, Mazzucchelli L, Cibas ES, Ali SZ. The Bethesda System for reporting thyroid fine-needle aspiration specimens. Am J Clin Pathol. 2010;134(2):343-4.

8. IBM Corporation. Released 2015. IBM SPSS Statistics for Windows, Version 23.0. Armonk, New York: IBM Corporation; 2015.

9. Sciacchitano S, Lavra L, Ulivieri A, Magi F, de Francesco GP, Bellotti C, et al. Comparative analysis of diagnostic performance, feasibility and cost of different test-methods for thyroid nodules with indeterminate cytology. Oncotarget. 2017;8:49421-42.

10. Du L, Wang Y, Sun X, Li H, Geng X, Ge M, et al. Thyroid cancer: trends in incidence, mortality and clinical-pathological patterns in Zhejiang Province, Southeast China. BMC Cancer. 2018;18:291. 